Brit. J. vener. Dis. (1964), 40, 256.

\title{
TREATMENT OF GONORRHOEA WITH NALIDIXIC ACID*
}

\author{
BY \\ LEONARD Z. OLLER \\ St. Luke's Hospital, Bradford
}

Nalidixic acid (Negram), a naphthyridine derivative, is a new chemotherapeutic agent, which is highly active in vitro against a wide range of Gramnegative organisms and has been reported to be particularly effective in vivo in urinary tract infections (Barlow, 1963; Lishman and Swinney, 1963; WardMcQuaid, Jichlinski, and Macis, 1963). Although in laboratory tests the gonococcus was found to be very sensitive to nalidixic acid, early clinical trials with doses usually recommended for urinary tract infections had been disappointing $\dagger$. The only positive results were reported from Mexico by Aparicio (1962), who treated thirty cases of gonorrhoea, 23 in the male and 7 in the female, with $1 \mathrm{~g}$. four times a day over 5 to 8 days and attained apparent cure in 24. However, he followed up the patients for not more than a week and the majority for less than 5 days.

\section{Present Study \\ Preliminary Investigations}

(1) Cultures of Neisseria gonorrhoeae obtained from eight unselected male and female patients attending the clinic at St. Luke's Hospital in Bradford were tested for sensitivity to nalidixic acid with $30 \mu \mathrm{g}$. disks and all were found to be sensitive.

(2) Two male Pakistanis with acute uncomplicated urethral gonorrhoea, aged 21 and 27 years respectively, were admitted to hospital for treatment with a single dose of $4 \mathrm{~g}$. (8 tablets) of Negram to assess the clinical effect and tolerance of this dose and to estimate the blood levels of the drug over 8 hours.

The patients were examined 6,24 , and 48 hours after treatment. The immediate response to nalidixic acid was comparable with that observed in penicillintreated cases. After 6 hours there was a considerable relief from symptoms and the previously purulent urethral discharge changed to a more scanty muco-

* Paper read at the MSSVD Meeting in Dublin on May 29, 1964. t Unpublished results in the files of the Bayer Products Company. purulent one in which extracellular pairs of distorted gonococci, larger and more deeply red-stained than usual, were found; the organisms could not be cultured. After 24 hours there was a further subjective improvement and the gonococcus disappeared from smears and cultures. After $\mathbf{4 8}$ hours there was a clinical relapse and the smears and cultures became positive again.

In both cases the gonococcus was sensitive in vitro to nalidixic acid and penicillin disks, both before treatment and after its failure. There were no sideeffects. The patients were successfully re-treated with 600,000 units procaine penicillin fortified by 200,000 units potassium benzyl-penicillin.

Blood samples for spectrophotofluorometric assay of nalidixic acid plasma levels were collected from the patients immediately before and 1, 2, 4, 6, and 8 hours after the drug was taken (Fig. 1, opposite). In one the peak was higher and the rise and decline steeper than in the other, but in both cases the level after 6 hours was still above $25 \mu \mathrm{g}$. per ml.

These preliminary investigations confirmed that nalidixic acid was active against the gonococcus both in vitro and in vivo, and that after a single dose of $4 \mathrm{~g}$. a high plasma level was attained within 1 or 2 hours and was maintained for 4 to 5 hours. It appeared that further trials to arrive at an effective dosage schedule were worth while.

\section{Clinical Material and Method}

Over a period of 8 weeks (from March 9 to May 4, 1964) seventy-four more male patients with acute uncomplicated urethral gonorrhoea were treated with nalidixic acid by various dosage schedules. Eight were treated in hospital.

Table I (opposite) shows the age and race distribution of the patients, including the two preliminary cases (making a total of 76); it is fairly representative of a cross-section of the male population attending the Bradford Clinic with gonorrhoea.

The Asians were mostly Pakistini; of the Europeans, thirteen were English, one Irish, and one Hungarian.

Treatment was started immediately after the diagnosis was made by Gram-stained smear, but in all but four 


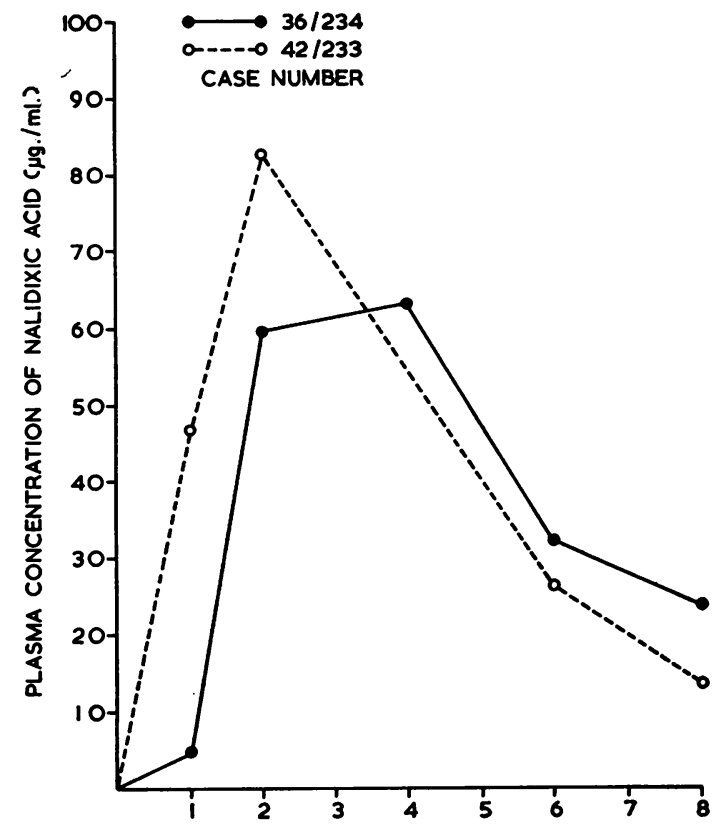

TIME AFTER MEDICATION (hrs)

FIG. 1.-Plasma levels of nalidixic acid in two cases after a single $4 \mathrm{~g}$. oral dose.

TABLE I

AGE AND RACE DISTRIBUTION

\begin{tabular}{c|c|c|c|c|c}
\hline \multirow{2}{*}{$\begin{array}{c}\text { Age } \\
\text { Group } \\
\text { (yrs) }\end{array}$} & Asian & $\begin{array}{c}\text { West } \\
\text { Indian }\end{array}$ & $\begin{array}{c}\text { African } \\
\text { Negro }\end{array}$ & European & Total \\
\hline $20-29$ & 30 & 3 & 1 & 7 & 41 \\
\hline $30-39$ & 16 & 4 & 1 & 6 & 27 \\
\hline $40-49$ & 3 & 2 & 0 & 1 & 6 \\
\hline $50+$ & 0 & 0 & 1 & 1 & 2 \\
\hline Total & 49 & 9 & 3 & 15 & 76 \\
\hline
\end{tabular}

cases, the diagnosis was confirmed by culture and the organisms were tested for disk-sensitivity to nalidixic acid and penicillin. In the first forty cases the commercially available $30 \mu \mathrm{g}$. nalidixic acid disks were used, but later the tests were performed with disks of $5 \mu \mathrm{g}$. potency.

Although all the patients, except those who have defaulted, are still kept under review, for the purpose of this report the tests for cure were performed 3 weeks after treatment, when the fluid expressed by prostatic massage was examined by smear and culture. Before that the patients were examined at least twice during the first week and the majority also twice during the second week.

As a rule cases which failed to respond to nalidixic acid were treated with penicillin, but seven patients were treated twice with nalidixic acid, viz. five after failure of penicillin, all again without success, and two after re-infection, both successfully. This gives a total of 83 treatments performed at nine different dosage schedules.

\section{Results}

The results in relation to dosage are shown in Table II.

TABLE II

DOSAGE AND RESULTS

\begin{tabular}{|c|c|c|c|c|c|c|}
\hline & \multirow{2}{*}{$\begin{array}{c}\text { Dosage } \\
\text { (g.) }\end{array}$} & \multicolumn{4}{|c|}{ Results } & \multirow{2}{*}{ Tota } \\
\hline & & \multirow{2}{*}{$\frac{\text { Failed }}{4}$} & \multirow{2}{*}{$\begin{array}{c}\begin{array}{c}\text { Suc- } \\
\text { ceeded }\end{array} \\
-\end{array}$} & \multirow{2}{*}{\begin{tabular}{|c|}
$\begin{array}{l}\text { Rein- } \\
\text { fected }\end{array}$ \\
- \\
\end{tabular}} & \multirow{2}{*}{$\begin{array}{c}\begin{array}{c}\text { De- } \\
\text { faulted }\end{array} \\
-\end{array}$} & \\
\hline \multirow{6}{*}{$\begin{array}{l}4 \mathrm{~g} . \\
\text { stat } \\
2 \mathrm{~g} . \\
6 \text {-hrly } \\
\text { for } .\end{array}$} & No further dose & & & & & 4 \\
\hline & One further dose & 3 & 1 & 1 & - & 5 \\
\hline & Two further doses & 5 & 3 & - & 1 & 9 \\
\hline & Three further doses & 1 & 3 & - & - & 4 \\
\hline & Four further doses & 10 & 14 & 1 & 2 & 27 \\
\hline & Five further doses & 3 & 10 & 3 & 3 & 19 \\
\hline \multicolumn{2}{|c|}{$\begin{array}{l}4 \text { g. stat + Variable Dosage } \\
\text { for } 1 \text { to } 2 \text { days }\end{array}$} & 6 & 1 & - & 1 & 8 \\
\hline \multicolumn{2}{|c|}{2 g. 6-hrly for $24 \mathrm{hrs}$} & 2 & 1 & - & - & 3 \\
\hline \multicolumn{2}{|c|}{ 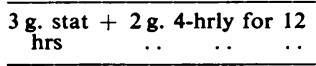 } & 2 & 2 & - & - & 4 \\
\hline \multicolumn{2}{|l|}{ Total } & 36 & 35 & 5 & 7 & 83 \\
\hline
\end{tabular}

The group treated with a single dose includes the two preliminary patients and two more who vomited after the first dose and discontinued treatment. In the following five groups, treatment consisted of an initial dose of $4 \mathrm{~g}$. and from one to five further doses of $2 \mathrm{~g}$. at 6-hrly intervals. In general the success rate increased with the number of doses given; in the group of nineteen patients treated with $14 \mathrm{~g}$. over $30 \mathrm{hrs}$, there were only three definite failures. The highest failure rate, excluding the single dose group, was in the group of eight patients who, after a loading dose of $4 \mathrm{~g}$., received from two to six subsequent doses of less than $2 \mathrm{~g}$. ( 1 or $1.5 \mathrm{~g}$.); here there were six failures in the seven patients who were followed up. Of the three patients who were treated with five equal doses of $2 \mathrm{~g}$. over $24 \mathrm{hrs}$, one was cured and two failed, and of the four who were treated with an initial dose of $3 \mathrm{~g}$. and three doses of $2 \mathrm{~g}$. over $12 \mathrm{hrs}$ two were cured and two failed.

All the re-infections occurred within the first fortnight and sexual re-exposure was admitted by the patients.

Of the defaulters*, five ceased to attend within 10 days of the completion of treatment, one received some tablets (presumably sulphonamides) from his own doctor during the follow-up period, and one was found to have syphilis for which treatment was started at the clinic; the last case is later described in detail.

* Since the report was read two of the defaulters re-appeared at the clinic with a re-infection: one 4 weeks after treatment with $12 \mathrm{~g}$. over $24 \mathrm{hrs}$, the other 6 weeks after treatment with $14 \mathrm{~g}$. over $30 \mathrm{hrs}$. 
Treatment failures (Table III) all became apparent within the first week. In three cases, of which two were treated with $12 \mathrm{~g}$. over $24 \mathrm{hrs}$ and one with $14 \mathrm{~g}$. over $30 \mathrm{hrs}$, the gonococcus was resistant to nalidixic acid in vitro; in two of them the urethral discharge remained purulent from the first and the gonococcus was found in smears and cultures after $24 \mathrm{hrs}$; in the third case the gonococcus was sensitive before treatment and resistant after the relapse which occurred on the third day.

Penicillin Resistant Cases (Table IV).-In thirteen cases the gonococcus was resistant in vitro to penicillin disks of potencies ranging from $\frac{1}{8}$ to $\frac{1}{2}$ of a unit. Six were successfully treated with nalidixic acid and seven failed, including the five in which the drug was given a second time. The failures were retreated with large doses of penicillin. In all the seven cases in which the gonococcus was tested for sensitivity to streptomycin, it was found to be resistant.

\section{TABLE IV}

CASES RESISTANT TO PENICILLIN

(Seven cases tested also against streptomycin-all resistant)

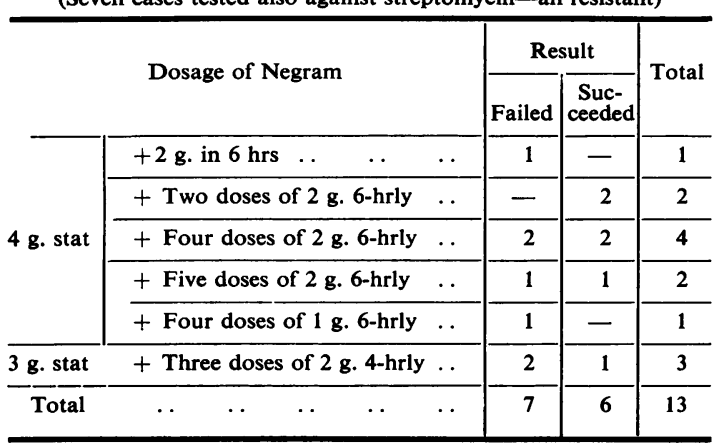

Patients Sensitized to Penicillin.-Two patients who were known to be sensitized to penicillin were successfully treated with nalidixic acid, $12 \mathrm{~g}$. over 24 $\mathrm{hrs}$ and $14 \mathrm{~g}$. over $30 \mathrm{hrs}$ respectively.

Plasma Levels (Fig. 2).-Plasma levels of the drug were estimated by spectrophotofluorometric assay at various times during and after treatment in the ten patients admitted to hospital and single estimations were made in nine of the patients treated at the clinic. Blood samples from the latter were collected between 20 and $24 \mathrm{hrs}$ and in two cases $30 \mathrm{hrs}$ after

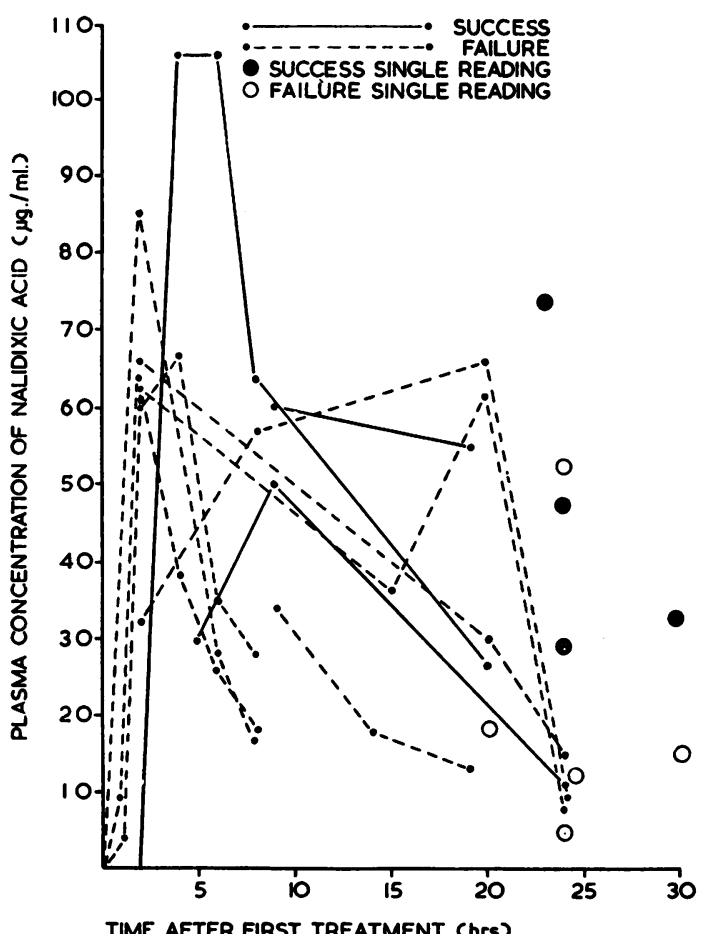

FIs. 2.-Plasma levels of nalidixic acid in nineteen cases at various dosage schedules.

TABLE III

RE-APPEARANCE OF ORGANISM IN FAILED CASES

\begin{tabular}{|c|c|c|c|c|c|c|c|c|c|c|c|c|}
\hline \multirow{2}{*}{\multicolumn{7}{|c|}{ Dosage }} & \multicolumn{6}{|c|}{ Second Positive Culture after Less than } \\
\hline & & & & & & & \multirow{2}{*}{$\begin{array}{c}2 \text { days } \\
4 \\
\end{array}$} & \multirow{2}{*}{$\frac{3 \text { days }}{-}$} & \multirow{2}{*}{$\frac{4 \text { days }}{-}$} & \multirow{2}{*}{$\begin{array}{c}5 \text { days } \\
-\end{array}$} & \multirow{2}{*}{$\frac{6 \text { days }}{-}$} & \multirow{2}{*}{$\frac{7 \text { days }}{-}$} \\
\hline \multirow{7}{*}{4 g. stat } & + No further tre & & . & . & . & $\ldots$ & & & & & & \\
\hline & $+2 \mathrm{~g}$. in $6 \mathrm{hrs}$ & . & . & .. & .. & . & 2 & 1 & - & - & - & - \\
\hline & + Two doses of & -hrly & . & . & .. & . & - & 1 & 2 & 2 & - & - \\
\hline & + Three doses o & & $\ldots$ & . & .. & $\ldots$ & - & - & - & 1 & - & - \\
\hline & + Four doses of & -hrly & $\ldots$ & $\ldots$ & $\ldots$ & $\ldots$ & 1 & 2 & 2 & 3 & 1 & 1 \\
\hline & + Five doses of & -hrly & .. & .. & .. & . & 2 & - & - & 1 & - & - \\
\hline & + Variable Dosa & o 2 das & & . & .. & . & 1 & 1 & 1 & - & 2 & 1 \\
\hline \multicolumn{2}{|c|}{2 g. 6-hrly for $24 \mathrm{hrs}$} & $\ldots$ & $\ldots$ & $\ldots$ & .. & . & - & - & - & 2 & - & - \\
\hline \multicolumn{2}{|c|}{3 g. stat +2 g. 4 -hrly for $12 \mathrm{hrs}$} & $\ldots$ & .. & .. & $\ldots$ & . & 1 & - & - & - & - & 1 \\
\hline
\end{tabular}


the first dose and between 5 and 8 hrs after the last dose of the drug. Plasma levels varied considerably irrespective of the dosage, but there was an obvious correlation between the plasma levels and the clinical response. Excluding the early cases in which the plasma level readings were limited to $8 \mathrm{hrs}$, all the successes but one are seen in the upper half and all the failures except one in the lower half of the graph, the level of $25 \mu \mathrm{g} . / \mathrm{ml}$. being more or less the dividing line. The single high plasma level associated with failure is explicable, as in this case the gonococcus was resistant to nalidixic acid in vitro.

Associated Disorders (Table V).--There were two cases of primary syphilis (briefly described later), nine of non-gonorrhoeal urethritis of which three were due to trichomonas infection, six of asymptomatic non-specific prostatitis which were detected on routine examination for cure of gonorrhoea 3 weeks after treatment, and four cases of scabies. Positive serological tests for syphilis were detected in two West Indians who had suffered from yaws in childhood and the gonococcal complement-fixation test was positive in a Pakistani with a history of two previous gonorrhoeal infections.

TABLE V

ASSOCIATED DISORDERS

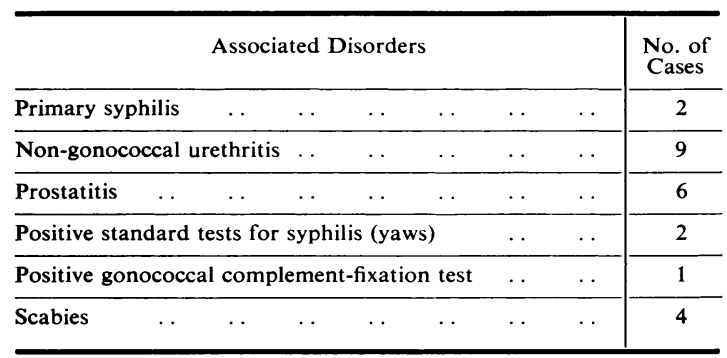

Of the two patients with primary syphilis one, a Pakistani aged 29, already had an ulcer on the glans penis when he was first examined and was found to be suffering from acute gonorrhoea. The ulcer was secondarily infected with pyogenic organisms and had been treated with an antiseptic ointment and the search for Treponema pallidum was unavailing. He was treated with nalidixic acid ( $4 \mathrm{~g}$. initially and two doses of 2 g.) and when he attended after 48 hours numerous Treponema pallida were detected in a clear exudate from the ulcer. Penicillin treatment was started and for convenience this patient was included in the group of defaulters. The serological tests in this case were positive.

The second patient, an unmarried Englishman aged 30 years, attended the clinic with gonorrhoea 11 days after sexual exposure. $\mathrm{He}$ was treated with $12 \mathrm{~g}$. of nalidixic acid over $24 \mathrm{hrs}$ and was seen on the 2 nd, 3 rd, and 7 th day after treatment. There was no urethral discharge from the 3 rd day onwards. When he attended on the 10th day a papule about $8 \mathrm{~mm}$. in diameter with a slightly eroded surface and well defined outlines was noted on the inner aspect of the prepuce and Treponema pallidum was demonstrated in the serum from the lesion. Before treatment with penicillin was started prostatic smears and cultures were taken; as they were negative, this patient was included in the group of nalidixic acid successes. The serological tests in this case were negative.

Side-effects (Table VI).- These occurred in twenty patients, but were not severe and did not prevent the patients from working. The most frequent complaint was dizziness which in seven cases was associated either with headache or with nausea. One patient had transient diplopia after each dose of the drug. The four patients who vomited were all Pakistanis working at night and all of them, it was later discovered, had received the first dose on an empty stomach. All of them were treatment failures. There were no side-effects in any of the patients who were treated in hospital.

TABLE VI

SIDE-EFFECTS IN 83 COURSES OF TREATMENT

\begin{tabular}{lll|c|c}
\hline \multicolumn{2}{c|}{ Side-Effects } & & No. of Cases & Percentage \\
\hline Dizziness & $\ldots$ & $\ldots$ & 15 & 18 \\
\hline Headache & $\ldots$ & $\ldots$ & 4 & 5 \\
\hline Vomiting & $\ldots$ & $\ldots$ & 4 & 5 \\
\hline Nausea . & $\ldots$ & $\ldots$ & 3 & 4 \\
\hline Diplopia & $\ldots$ & $\ldots$ & 1 & 1 \\
\hline
\end{tabular}

\section{Conclusion}

The results of this trial indicate that nalidixic acid has a definite antigonorrhoeal action. In spite, however, of the high sensitivity of the gonococcus to the drug in vitro, in clinical practice large doses are needed to attain a significant proportion of cures. The drug should be taken at intervals of not less than $6 \mathrm{hrs}$ over at least $30 \mathrm{hrs}$; individual doses should not be less than $2 \mathrm{~g}$. and an initial loading dose of $4 \mathrm{~g}$. is indicated. Even then in some patients an adequate plasma level, which appears to be in the region of 25 $\mu \mathrm{g} . / \mathrm{ml}$. may not be reached or maintained owing probably either to poor absorption or to rapid elimination of the drug.

Obviously nalidixic acid has all the disadvantages of any drug requiring multiple doses by mouth and cannot be recommended for the routine treatment of gonorrhoea. The fact, demonstrated by two cases in 
this series, that it has no effect whatever upon Treponema pallidum makes it a probable drug of choice in cases of gonorrhoea in which a concomitant early syphilis is suspected. It may also be useful for treatment of gonorrhoea in patients sensitized to penicillin.

\section{Summary}

76 male patients with acute uncomplicated urethral gonorrhoea were treated with nalidixic acid using nine different dosage schedules.

In general the success rate increased with the increase in dosage and a significant proportion of cures was attained with an initial dose of $4 \mathrm{~g}$. and five further doses of $2 \mathrm{~g}$. given at 6-hrly intervals.

Plasma levels of the drug were assayed in nineteen patients and the results suggest that $25 \mu \mathrm{g} . / \mathrm{ml}$. is probably the lowest effective level.

In two cases of concomitant primary syphilis, nalidixic acid showed no effect upon Treponema pallidum.

The unusually large doses of the drug which were used in this trial were well tolerated and the sideeffects (which occurred in twenty patients) were on the whole not severe.

It is concluded that nalidixic acid cannot be recommended for routine treatment of gonorrhoea, but that it may be useful in cases in which concomitant early syphilis is suspected and in cases of sensitization to penicillin.

I am indebted to Dr G. B. Hill and Mr H. W. Hurst of the Clinical Evaluation Unit of the Bayer Products
Company for the generous supply of Negram tablets and disks and for practical help; to $\mathrm{Mr} \mathrm{A}$. Robertson of Winthrop Laboratories, Newcastle upon Tyne, for estimations of the drug plasma levels; and to Dr H. G. Smith, Director of the Public Health Laboratory in Bradford, for sensitivity tests.

\section{REFERENCES}

Aparicio, A. (1962). Acta med. hidalg., 17, 85.

Barlow, A. M. (1963). Brit. med. J., 2, 1308.

Lishman, I. V., and Swinney, J. (1963). Brit. J. Urol., 35, 116.

Ward-McQuaid, J. F. N. C., Jichlinski, D., and Macis, R. (1963). Brit. med. J., 2, 1311.

Traitement de la gonorrhée par l'acide nalidixique

\section{RÉSUMÉ}

76 patients atteints de gonorrhée urétrale aigüe non compliquée furent traités par l'acide nalidixique en utilisant neuf méthodes différentes. En général les succès augmentèrent avec la dose et une proportion notoire de guérisons fut obtenue en traitant par une dose initiale de $4 \mathrm{~g}$. suivie de 5 doses de $2 \mathrm{~g}$. données à 6 heures d'intervalle.

Le taux plasmatique des médicaments fut déterminé chez 19 patients et les résultats suggérèrent que $25 \mu \mathrm{g} . / \mathrm{ml}$. est probablement le taux le plus bas d'efficacité.

Dans deux cas de syphilis primaire surajoutée l'acide nalidixique n'eut aucun effet sur le tréponème pâle.

Les doses, plus importantes que d'habitude, utilisées dans cette expérience furent bien tolérées et les effets secondaires qui survinrent chez vingt malades ne furent pas sévères dans l'ensemble.

En conclusion l'acide nalidixique ne peut être recommandé pour le traitement de routine de le gonorrhée, mais il peut être utile en cas de syphilis précoce surajoutée et en cas de sensibilisation à la pénicilline. 